\title{
Microwave Structural Health Monitoring Sensor for Deformation Measurement of Bended Steel Structures: Influence of Curvature Effect
}

\author{
Przemyslaw LOPATO, Michal HERBKO \\ Dept. of Electrical and Computer Engineering, West Pomeranian University of Technology, \\ al. Piastow 17, 70-310 Szczecin, Poland \\ plopato@zut.edu.pl, michal.herbko@zut.edu.pl \\ Submitted May 26, 2017 / Accepted August 17, 2017
}

\begin{abstract}
In this paper the utilization of microstrip antenna sensor for deformation monitoring in bended steel structures is presented. This kind of sensing element can be used in structural health monitoring systems. Deformation measurement by patch sensor is based on the reflection coefficient $S_{11}$ investigation. So far, relationship between resonant frequency and change of patch dimensions was considered in literature only for planar microstrip sensors. In case of samples subjected to bending process the sensor geometry became non-planar. This fact affects measured resonant frequency, thus it should be studied. In order to analyze influence of patch sensor curvature on resonant frequency during bending process Finite Element Method (FEM) simulations were carried out. Results of analysis were experimentally verified.
\end{abstract}

\section{Keywords}

Microstrip antenna sensor, nondestructive testing, deformation measurement, structural health monitoring, microwave technique

\section{Introduction}

In order to assure the safety of ships, aircrafts or civil structures various nondestructive testing (NDT) techniques are utilized. Nowadays periodic NDT inspection is often displaced or supported by Structural Health Monitoring (SHM). This trend is caused by complicated procedures of traditional inspections and high cost of maintenance. In case of some aspects SHM can be more effective than periodical inspection because it enables to oversee the state of structures in real time. Additionally, a good designed SHM system may check and inform about state of structure after extreme weather anomalies e.g. earthquake, hurricane or heavy snowfall [1-3]. SHM technique utilized in aircrafts provides the high level of safety, decreases the cost of maintenance and reduces the service time [4]. Typical systems consist of sensors, central data repository and a set of algorithms which allow to detect, localize, identify and predict potential damage. The information from sensors is usually sent by cables to data acquisition system. It increases the cost of installation and maintenance [5-7]. In case of large buildings such as bridges, the cost of additional cable installation is high. Moreover, because of the spread character of this sensor network, its conservation and service can be more problematic. Besides, there is an additional element, which can be damaged. Therefore, SHM systems are mainly applied in new civil structures. The cheap and wireless sensor networks will enable application of monitoring systems even in case of old structures. In this paper, the proposed deformation sensor was utilized for the evaluation of bended St3s steel sample (Poland). This type of steel is no longer utilized in new projects, but still many older constructions made of St3s are in service.

We may split SHM methods into two groups - global and local ones. The global SHM systems are based on visual inspection, infrared thermography, ultrasonics or acoustics. Nevertheless, for many large systems, global monitoring is impractical because of the lack of sensitivity of global features regarding local damages [8], [9]. For this reason in case of big structures local methods of damage detection should be utilized. They allow to check critical points of construction. In SHM technique many type of sensors are used such as resistive and capacitive strain gauges and fiber optic sensors [10].

The utilization of microstrip antenna sensors to stress/deformation evaluation or crack growth measurement became an object of interest of many researchers in the last few years [10-27]. Both mentioned applications rely on the reflection coefficient $S_{11}$ study. In case of deformation measurement the strong relationship between resonant frequency $f_{\mathrm{r}}$ of microstrip sensor and patch resonator dimensions was utilized. In case of the second application, a crack in the ground plane will force the current to flow around it. As a result, the effective electrical length of the patch antenna increases, which shifts the antenna resonant frequency to a lower value.

Up to now, microstrip sensors with various shapes of 
patches were used for strain investigation. In case of inplane tension subjected structures only rectangular patch sensors were utilized [13], [19], [21], [22], [25]. Deformation of bended elements was evaluated by rectangular [11], [27], circular [10], [17], [18], [20] and other shape of patch [15], [16] microstrip sensors. However, the influence of curvature effect on resonant frequency in these cases was not considered. In this paper considerable influence of curvature of rectangular patch on resonant frequency was noticed. This effect was described in details by Kin-Lu Wong for structures utilized in telecommunication [28], but in our case the resonant frequency is dependent on both: the change of the patch dimensions and curvature effect. Thus, an experiment and numerical analysis (in which deformation was evaluated by patch sensor) were carried out. Moreover the influence of curvature effect on resonant frequency for the designed sensor was determined.

\section{Sensor Design}

Microstrip antennas, filters and transmissions lines can be fabricated in printed circuit board (PCB) technology. They consist of a microstrip structure separated from a ground plane by a dielectric material [29-32]. In this paper a microstrip antenna sensor fed by a microstrip line is designed, as shown in Fig. 1. This way of feed is easy to fabricate and integrate with electronics.

At first the transmission-line model was utilized to design a microstrip antenna sensor and the correctness was validated by FEM analysis. Antenna sensors were developed on the double-side polymer laminate of thickness $0.5 \mathrm{~mm}$ (relative permittivity of 4.5 ). The patch, microstrip line and ground are made of copper (layer thickness of $35 \mu \mathrm{m})$. Patch sensor was designed for operation frequency of $12 \mathrm{GHz}$ at the fundamental mode [29]. The results of

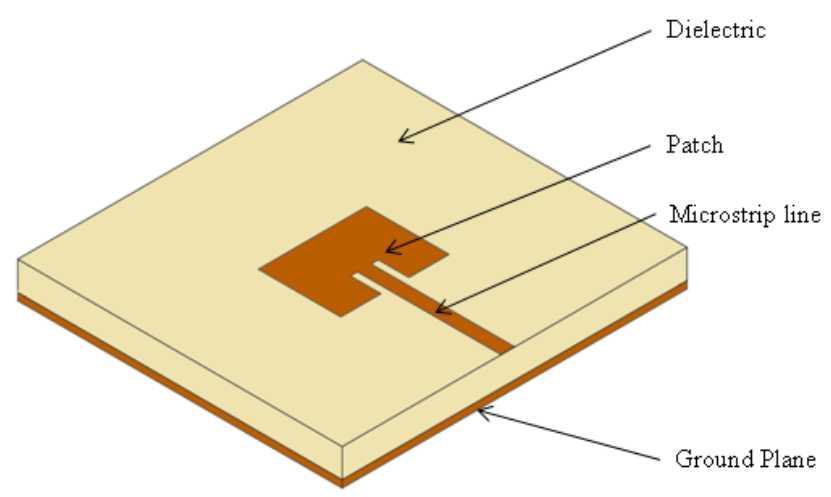

Fig. 1. Microstrip sensor fed by microstrip line.

\begin{tabular}{|c|c|}
\hline Designed parameter name & Parameter value \\
\hline$W$ & $7.538 \mathrm{~mm}$ \\
\hline$\varepsilon_{\text {reff }}$ & 4.056 \\
\hline$\Delta L$ & $0.228 \mathrm{~mm}$ \\
\hline$L$ & $5.75 \mathrm{~mm}$ \\
\hline$y_{0}$ & $2.136 \mathrm{~mm}$ \\
\hline
\end{tabular}

Tab. 1. Results of transmission line model calculations [20].

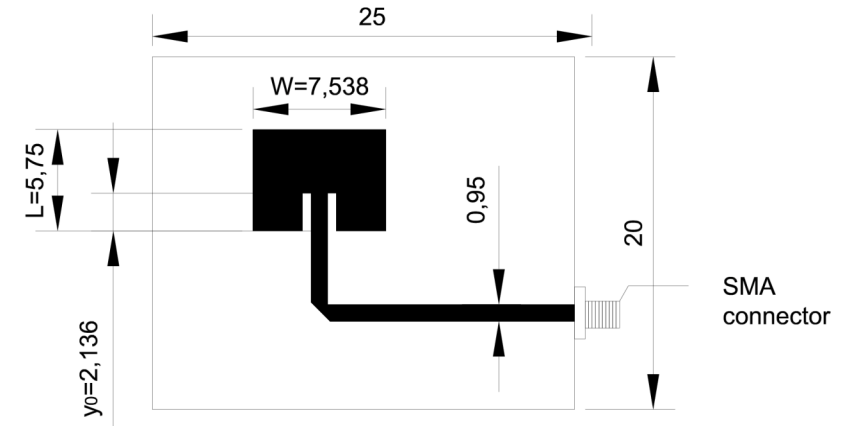

Fig. 2. View and dimensions (in $\mathrm{mm}$ ) of the designed sensor [20].

calculation obtained by transmission-line model are presented in Tab. 1, whereas dimensions of the designed microstrip SHM sensor are shown in Fig. 2.

\section{Experimental Setup}

In this article the utilization of microstrip antenna to evaluation of deformation in bended steel elements was studied. The scheme of experiment is shown in Fig. 3. One side of planar steel sample (beam sample) was fixed to static holding element and the opposite side was loaded using a set of weights in order to obtain various deformation levels. The top surface of sample was extended, whereas the bottom was shortened with increasing of load. For this reason, the investigated sensors were adhesively connected to both sides of beam sample, which was made of St3s construction steel - in accordance with Polish standards PN-88 H-84020 (an equivalent for S235JRG2 in European standards EN 10025). The parameters of St3s steel are presented in Tab. 2. The maximum value of load equals $0.9 \mathrm{~kg}$ for considered sample (within elastic range of the material stress-strain relationship).

Both transducers were placed in the same distance from loading force on opposite sides of sample in order to obtain the same strain level. Displacement $u_{\mathrm{y}}$ along the sample is presented in Fig. 4. The proposed placement of the transducers cannot be determined just by $y$-component

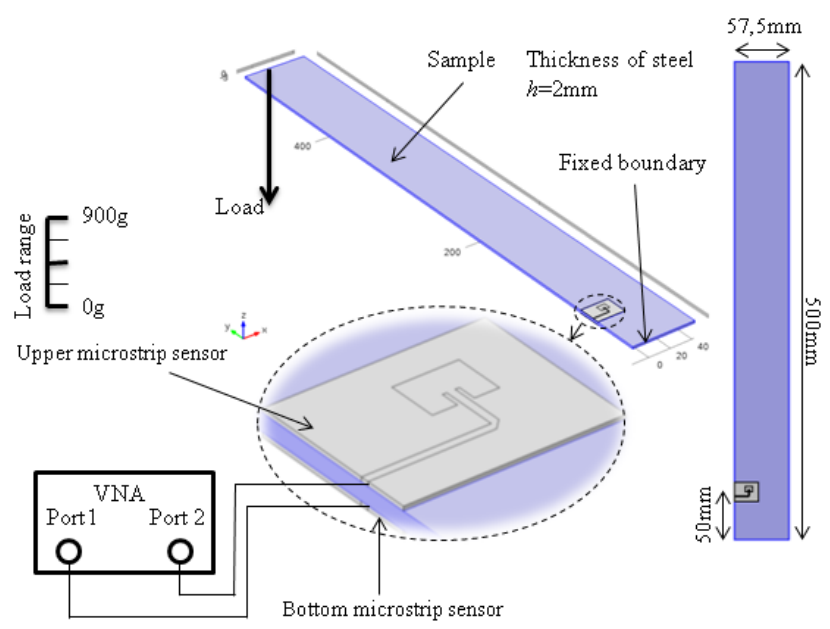

Fig. 3. Scheme of experiment and dimensions of sample. 


\begin{tabular}{|c|c|}
\hline Parameter name & Parameter value \\
\hline Young's modulus $E$ & $200 \mathrm{GPa}$ \\
\hline Yield point & $235 \mathrm{MPa}$ \\
\hline Limit state & $380 \mathrm{MPa}$ \\
\hline Bending Limit state & $145 \mathrm{MPa}$ \\
\hline Density & $7850 \mathrm{~kg} / \mathrm{m}^{3}$ \\
\hline
\end{tabular}

Tab. 2. Mechanical properties of St3s (S235JRG2) steel according to PN-88 H-84020 (EN10025).

of displacement $u_{\mathrm{y}}$, because it only shows the summary of displacement. Therefore, the position of sensors was determined by the local change of displacement. The highest displacement derivative values are from 10 to $70 \mathrm{~mm}$ as shown in Fig. 5. Thus, $50 \mathrm{~mm}$ distance from a fixed boundary was selected.

The microstrip sensors were produced by the photolithography process. Two identical transducers were created. The manufactured sensor is presented in Fig. 6. Antenna sensors have been made on the double-side polymer laminate of thickness of $0.5 \mathrm{~mm}$, relative permittivity of 4.5. The patch, microstrip line and ground are made of copper (layer thickness of $35 \mu \mathrm{m}$ ). The antenna is probe fed with a $50 \Omega$ SMA connectors.

The microstrip antenna sensors were fixed using cyanoacrylate glue on the top and bottom surface of the

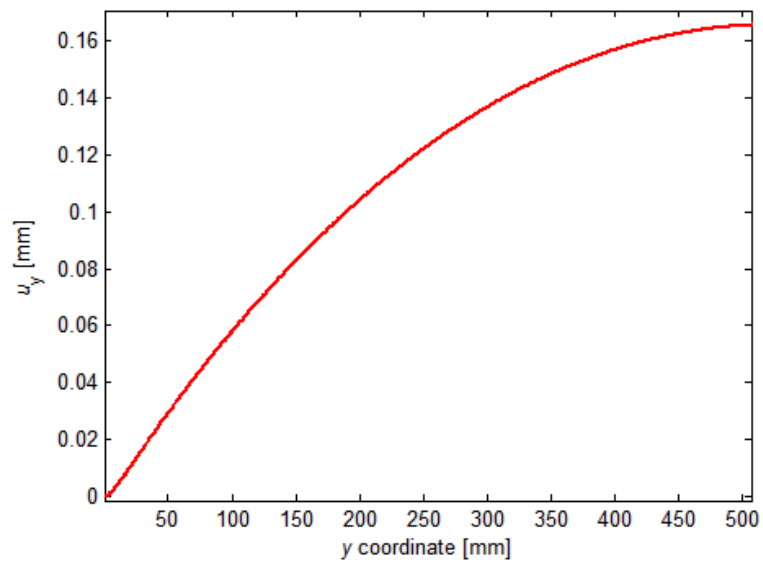

Fig. 4. Displacement $u_{\mathrm{y}}(y$ component $)$ along the beam sample.

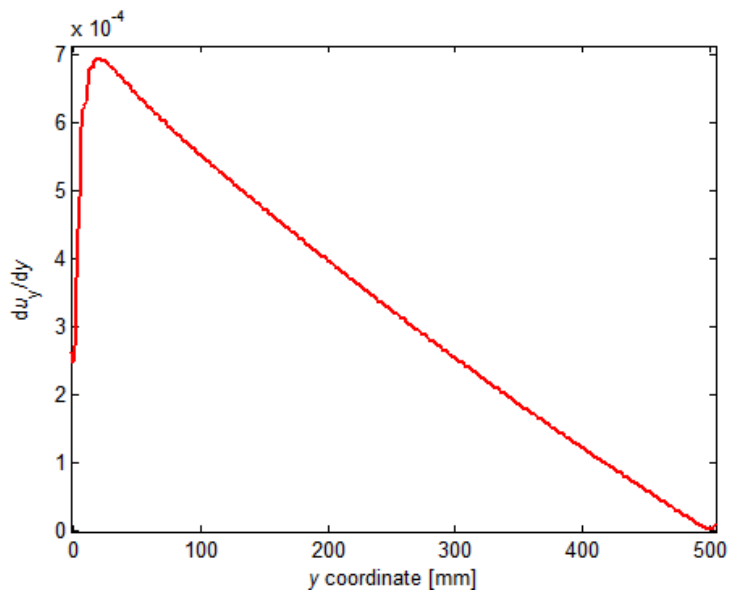

Fig. 5. Derivative of $u_{\mathrm{y}}$ along of the beam sample $(y$ component).

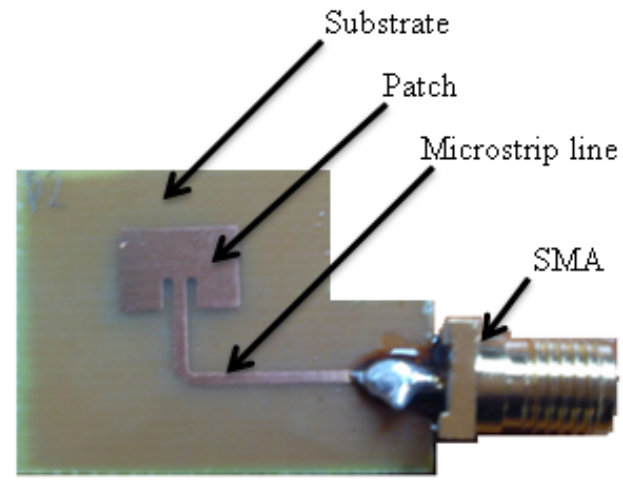

Fig. 6. Photo of the manufactured microstrip SHM sensor [20].

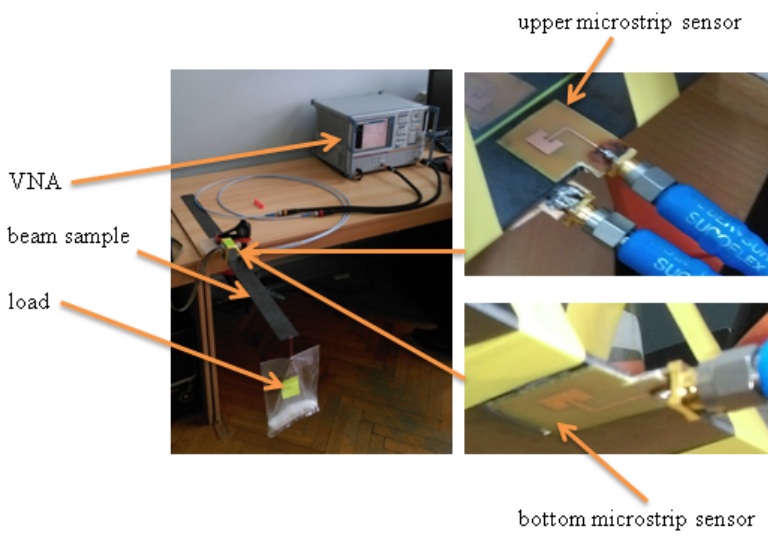

Fig. 7. Photo of the measuring system.

sample as shown in Fig. 3 and 7. This adhesive connection allows transmission of sample deformation to microstrip sensors. Measurements were carried out using Rohde\&Schwarz ZVB20 vector network analyzer in $10 \mathrm{MHz}-20 \mathrm{GHz}$ frequency range with step of $2 \mathrm{MHz}$. The photo of the measuring system is shown in Fig. 7. The sample was attached to the static holding element and the other side was loaded with different weights in order to introduce different deformation. Change of utilized load caused damped oscillations of the sample. For this reason the $S_{11}$ coefficient was measured 60 seconds after load addition.

\section{Results of Experiments}

\subsection{Numerical Analysis}

Numerical and experimental analyses were carried out. In order to evaluate the proposed sensor FEM (Finite Element Method) numerical model was developed in Comsol Multiphysics environment. Solid mechanics module was used in order to obtain deformation of steel sample and sensor geometry [33]. Afterwards, the RF module enabled calculation of reflection coefficient for the deformed sensor [34].

The numerical model with the mechanical scheme and the calculated total displacement for maximum load (within 


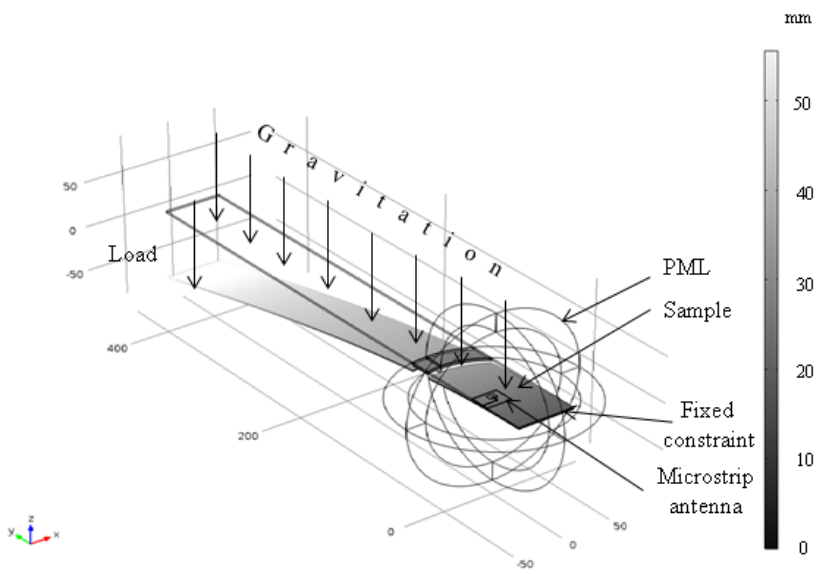

Fig. 8. FEM numerical model of the experimental setup with calculated total displacement for maximum load (grey level) [20].

elastic range of the material stress-strain relationship) are presented in Fig. 8. The sample is affected by both the force of gravity and the force attached to its end.

The patch sensors are in the center of two concentric spheres. The inner sphere acts as an environment of the sensor - it enables the propagation of electromagnetic waves. The outer part of the bigger sphere (outside the inner sphere) enables absorption of electromagnetic waves generated by the transducers (Perfectly Matched Layers, PML). The computational mesh has 235265 tetrahedral elements. The reflection coefficient $S_{11}$ represents the power reflected from the antenna related to the incident one. The coefficient is determined in frequency domain. The calculated frequency response is presented in Fig. 9, this is a typical resonant characteristics for radiating microstrip structures. The frequency characteristics of $S_{11}$ parameter was calculated while the sample was not affected by any force. The value of $f_{\mathrm{r}}$ without any load was designated. The simulation was carried out in $4-15 \mathrm{GHz}$ frequency range with step of $1 \mathrm{MHz}$. This step length ensured sufficient accuracy of $f_{\mathrm{r}}$ determination. The electric field distribution for resonant frequency is illustrated in Fig. 10.

In the considered setup the deformation along the sample is dominant, thus it is assumed, that it is measured

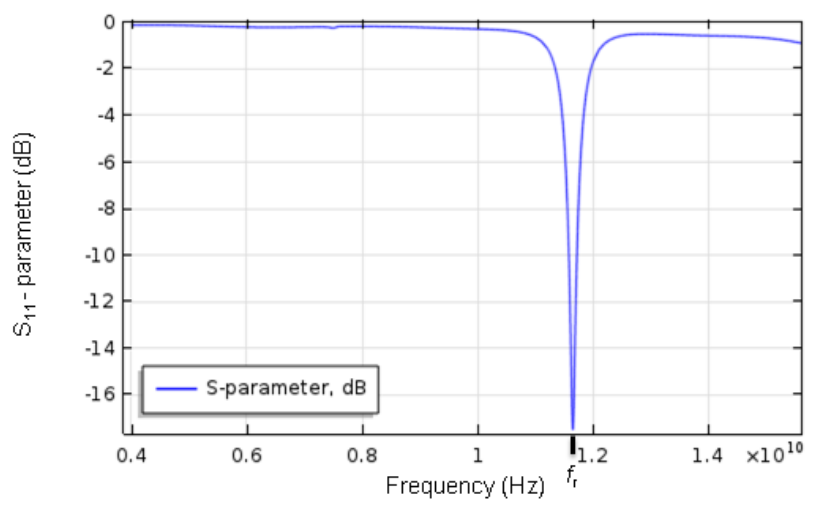

Fig. 9. Reflection coefficient for utilized sensors [20].

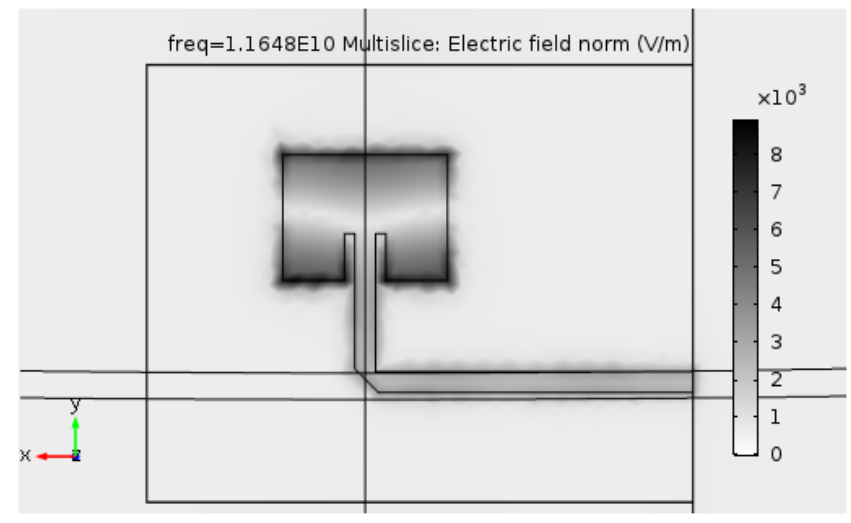

Fig. 10. Electric field for resonant frequency.

by the change of the patch length $\Delta L$. The relationship between the change of the patch length $\Delta L$ and the mass of the load $m$ is presented in Fig. 11. If it is assumed that only the change in the patch dimensions influences resonant frequency (influence of curvature is not considered), the $f_{\mathrm{r}}$ value for upper sensor should be decreased, whereas for the bottom patch sensor ought to be increased with the rise of load. It is caused by the change of the microstrip sensor effective length. The patch of the upper sensor is lengthened and the patch of the bottom sensor is shortened. The results for upper microstrip sensor were predictable as shown in Fig. 12 and 14. The resonant frequency of this sensor was decreased while increasing the load (longer patch causes lower $f_{\mathrm{r}}$ ). In case of the bottom sensor it is different (presented in Fig. 13 and 14). For small elongations the resonant frequency of this transducer was increased, but subsequently it was decreased while increasing the load. This effect will be analyzed more detailed later in this section. In Fig. 14 the shifts of the resonant frequency in function of the patch length change for both sensors were presented. Nonzero value of $\Delta f_{\mathrm{r}}$ and $\Delta L$ (Fig. 11) in case of $m=0 \mathrm{~g}$ is caused by the force of gravity. Cubic polynomial approximation was used to improve the accuracy of the resonant frequency evaluation.

Numerical analysis exhibited that the shift of the resonant frequency was not only depended on the length of the patch. Thus, the curvature effect will be investigated. In order to determine the influence of this effect two numerical models: convex and concave (illustrated in Fig. 15 and 16) were considered. The influence of radius $r$ on the resonant frequency was studied by these numerical models. During the calculations the length of $r$ was changed, while the dimensions of patch, microstrip line, width and length of substrate curve were constant.

The curvature effect for the upper sensor was studied by the convex model and for the bottom sensor it was investigated by the concave model. The value of $r$ decreased with raising load. The curvature effect has opposite influence on resonant frequency towards changing of patch length, but in case of the upper sensor this effect is less significant (comes out for smaller radius) than in case of the bottom sensor (Fig. 17). For the bottom sensor, a re- 
duction of the patch length caused the growth of $f_{\mathrm{r}}$, on the other hand the curvature effect causes decrease of resonant frequency. In case of the upper sensor, the increase of the patch length causes decreasing $f_{\mathrm{r}}$, whereas the curvature effect entails increasing of resonant frequency with raising load.

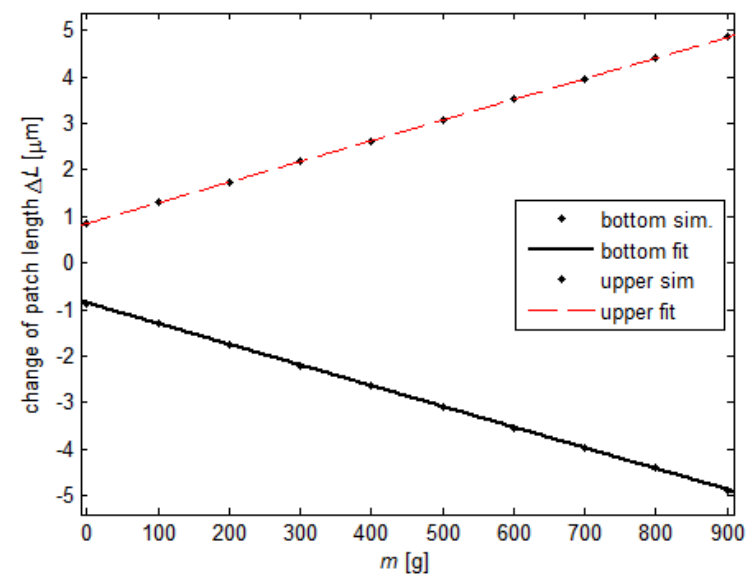

Fig. 11. Relationships between the mass of the load and the change of the patch length derived by the simulation model.

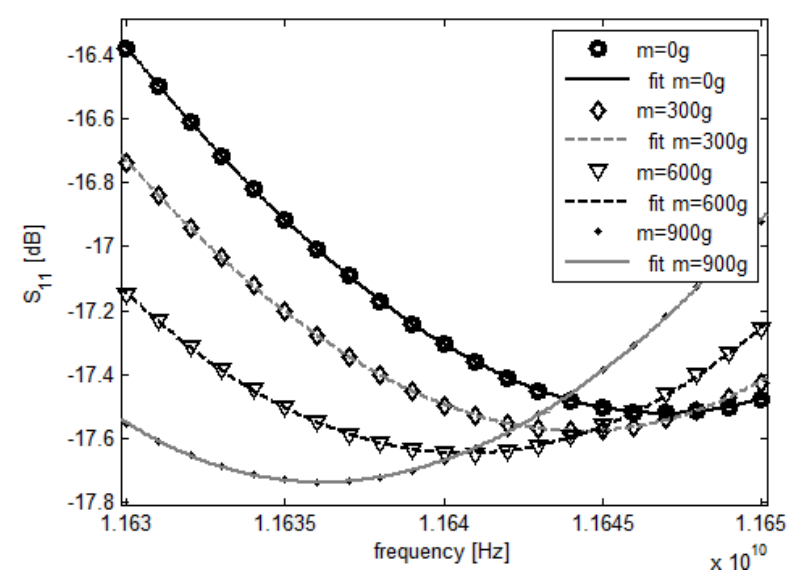

Fig. 12. Reflection coefficient $S_{11}$ of the upper sensor for different loads [20].

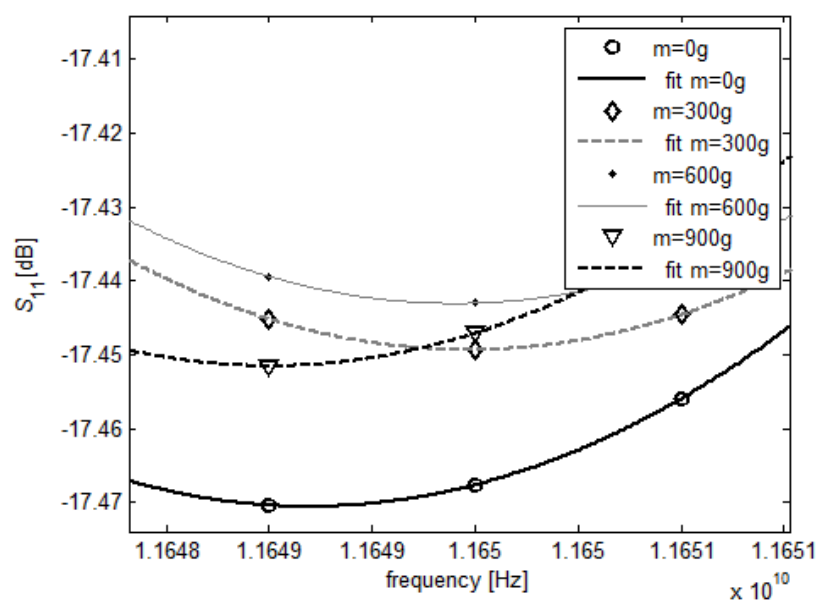

Fig. 13. Reflection coefficient $S_{11}$ of the bottom sensor for different loads.

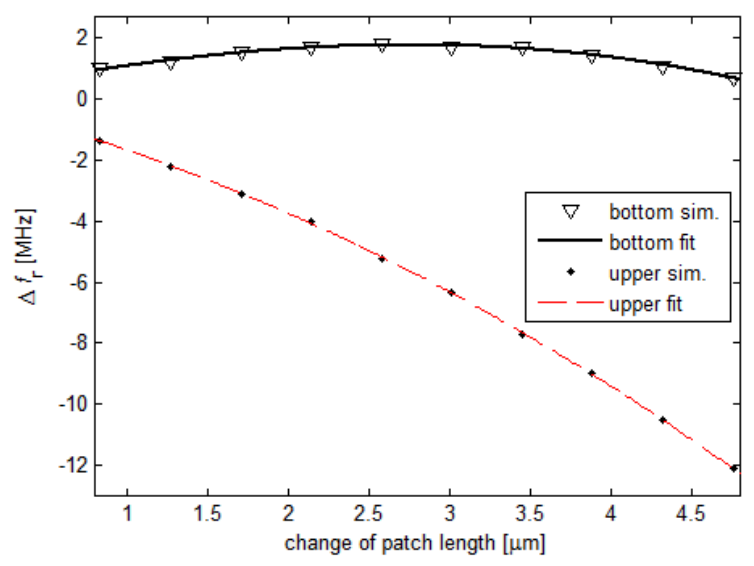

Fig. 14. Deformation evaluation by both sensors (numerical analysis).
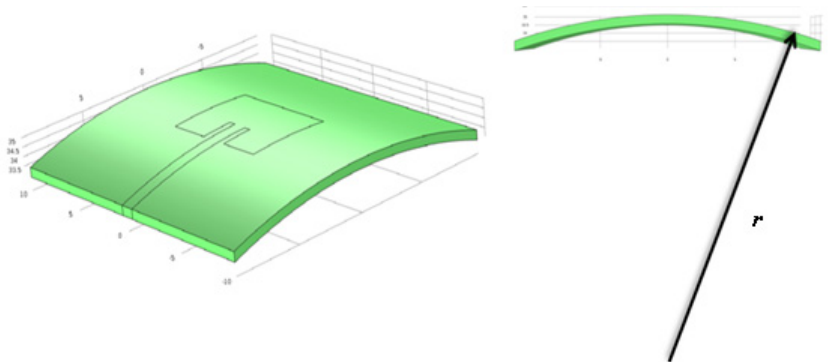

Fig. 15. Convex model.
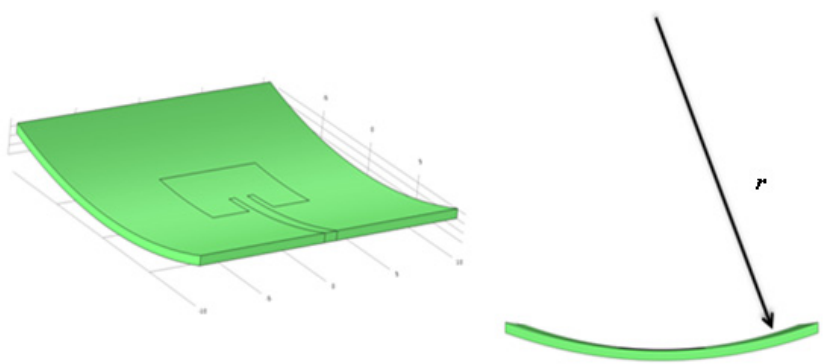

Fig. 16. Concave model.

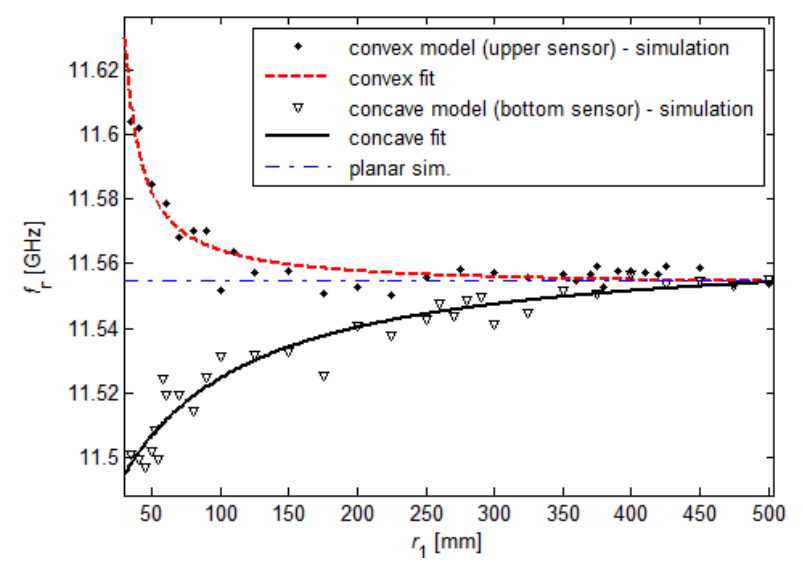

Fig. 17. Dependence of the curvature radius and resonant frequency.

\subsection{Results of Experimental Analysis}

In order to verify the correctness of FEM simulations, experimental analysis was carried out. The results of meas- 
urements are shown in Fig. 18. The resonant frequency of the upper sensor was decreased with the increasing load. This shift was caused by the increase of the effective length of the patch. The influence of the curvature effect for this microstrip sensor was relatively small. In the case of the bottom microstrip sensor, the impact of this phenomenon on the resonant frequency was higher than for the upper patch sensor, so that utilization of the convex model of transducer is recommended.

\section{Conclusions}

In this article the deformation measurement in bended steel element by rectangular microstrip sensor was investigated. The proposed sensors were adhesively connected to both sides of a sample, thus during the bending process the sensor geometry became non-planar. For the designed sensor the influence of the curvature effect on resonant frequency was investigated. Furthermore, it should be pointed that the impact of the change of the patch length in connection with the curvature effect was considered, which has not been presented in literature yet. A good agreement of simulated and measured results was obtained. Comparisons of the results are presented in Fig. 19. However, this type of sensor should be used carefully for deformation measurements in bending elements, because the curvature

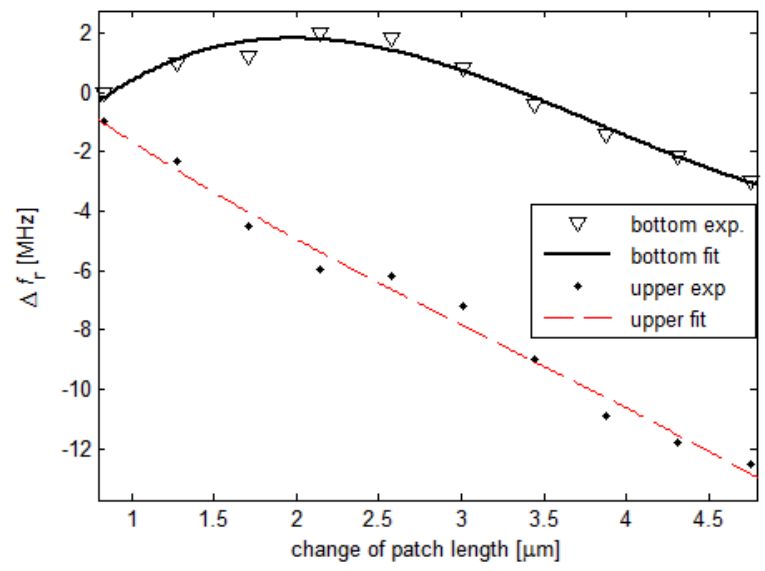

Fig. 18. Deformation evaluation by both sensors (experimental analysis).

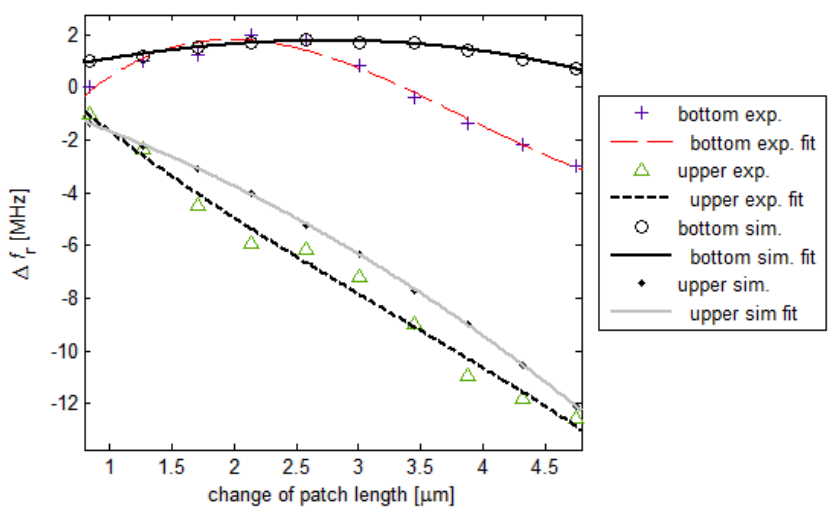

Fig. 19. Comparison of simulation and measurement results. effect has opposite impact on the resonant frequency than changing the length of the patch. Therefore, the place of attaching the sensor ought to be well selected.

Microstrip SHM sensors could be further developed for wireless Structural Health Monitoring application. It may increase the area of SHM techniques application and thereby increase the safety of structures. In the further work the directional characteristics of the rectangular microstrip sensor will be determined and the influence of the curvature effect for other directions will be studied. One of the ideas to minimize the influence of the curvature effect is application of tunable antennas [35-37].

\section{References}

[1] NI, Y.Q., WONG, K. Y. Integrating bridge structural health monitoring and condition-based maintenance management. In Proceedings of the $4^{\text {th }}$ International Workshop on Civil Structural Health Monitoring. Berlin (Germany), Nov 2012. ISBN: 9783940283450

[2] RAINIERI, C., FABBrocino, G., COSENZA, E. Structural health monitoring systems as a tool for seismic protection. In Proceedings of the $14^{\text {th }}$ World Conference on Earthquake Engineering. Beijing (China), Nov 2008.

[3] WILDE, K. Structural health monitoring systems for buildings. Systemy monitoringu obiektów budowlanych (Systemy monitoringu obiektów), XXVI Konferencja Naukowo-Techniczna, awarie budowlane. Międzyzdroje (Poland), 2013, p. 123-140. ISBN: 978-83-7663-151-6 (in Polish)

[4] BOCKENHEIMER, C., SPECKMANN, H., SHM AIRBUS/IW TEAM. Validation, verification and implementation of SHM at Airbus. In $9^{\text {th }}$ International Workshop on Structural Health Monitoring. Stanford (USA), Sep 2013.

[5] CELEBI, M. Seismic instrumentation of buildings (with emphasis on federal buildings). Technical Report No.0-7460-68170, United States Geological Survey, Menlo Park (USA), 2002.

[6] LYNCH, J. P., LOH, K. J. A summary review of wireless sensors and sensor networks for structural health monitoring. The Shock and Vibration Digest, 2006, vol. 38, no. 2, p. 91-128. DOI: $10.1177 / 0583102406061499$

[7] LYNCH, J. P., PARTRIDGE, A., LAW, K. H., et al. Design of piezoresistive MEMS-based accelerometer for integration with wireless sensing unit for structural monitoring. Journal of Aerospace Engineering, 2003, vol. 16, no. 3, p. 1-7. DOI: 10.1061/(ASCE)0893-1321(2003)16:3(108)

[8] UGALDE, U., ANDUAGA, J., MARTINEZ, F., et al. Novel SHM method to locate damages in substructures based on VARX models. Journal of Physics: Conference Series, 2015, vol. 628. DOI: $10.1088 / 1742-6596 / 628 / 1 / 012013$

[9] HOU, J. JANKOWSKI, L., OU, J. Structural damage identification by adding virtual masses. Structural and Multidisciplinary Optimization, 2013, vol. 48, no. 1, p. 59-72. DOI: 10.1007/s00158-012-0879-0

[10] DALIRI, A., GALEHDAR, A., ROWE, W. S., et al. Utilising microstrip patch antenna strain sensors for structural health monitoring. Journal of Intelligent Material Systems and Structures, 2011, vol. 23, no. 2, p. 169-182. DOI: $10.1177 / 1045389 X 11432655$

[11] TATA, U. S. Study of Patch Antennas for Strain Measurement. University of Texas, Arlington (USA), August 2008. 
[12] WANG, W., GE, H., LIU, T., et al. Study of patch antennas for strain measurement. Electromagnetic Nondestructive Evaluation (XVIII), 2015, vol. 40, p. 313-321. DOI: 10.3233/978-1-61499509-8-313

[13] SHARAMA, N., THAKARE, V. V. Analysis of microstrip rectangular patch antenna as a strain sensor. International Journal of Research in Electronic and Communication Technology, 2015, vol. 2, no. 2, p. 17-19. ISSN : 2348-9065

[14] HUANG, H. Flexible wireless antenna sensor: A review. IEEE Sensors Journal, 2013, vol. 13 no. 10, p. 3865-3872. DOI: 10.1109/JSEN.2013.2242464

[15] DALIRI, A., GALEHDAR, A., JOHN, S., et al. Slotted circular microstrip patch antenna application in strain based structural health monitoring. In Proceedings of the $14^{\text {th }}$ Australian International Aerospace Congress. Melbourne (Australia), 2011. 12 p. ISBN: 9780987086310

[16] DALIRI, A., WANG, C. H., JOHN, S., et.al. Multidirectional circular microstrip patch antenna strain sensor. In Proceedings of ASME 2011 Conference on Smart Materials, Adaptive Structures and Intelligent Systems. Scottsdale (USA), Sep 2011, p. 481-487. DOI: 10.1115/SMASIS2011-5065

[17] DALIRI, A., JOHN, S., GALEHDAR, A., et al. Strain measurement in composite materials using microstrip patch antennas. In Proceedings of ASME 2010 Conference on Smart Materials, Adaptive Structures and Intelligent Systems. Philadelphia (USA), Sep. 2010, p. 591-598. DOI: 10.1115/SMASIS2010-3703

[18] DALIRI, A., GALEHDAR, A., JOHN, S., et al. Circular microstrip patch antenna strain sensor for wireless structural health monitoring. In The World Congress on Engineering. London (UK), June 2010, p. 1173-1178. ISBN: 9789881821072

[19] BENCHIROUF, A., ZICHNER, R., MULLER, C., et al. Electromagnetic simulation of flexible strain sensor based microstrip patch antenna. International Journal of Microwave and Optical Technology, 2015, vol. 10, no. 6-I, p. 397-401. ISSN: 1553-0396

[20] LOPATO, P., PSUJ, G., HERBKO, M., et al. Evaluation of stress in steel structures using electromagnetic methods based on utilization of microstrip antenna sensor and monitoring of $\mathrm{AC}$ magnetization process. Informatics, Control, Measurement in Economy and Environment Protection IAPGOS, 2016, vol. 6, no. 4, p. 32-36. DOI: $10.5604 / 01.3001 .0009 .5186$

[21] PSUJ, G., SZYMANIK, B., LOPATO, P., et al. Multimodal monitoring of damage in steel construction elements during fatigue life. Welding Technology Review, 2016, vol. 88, no. 10, p. 108-113. ISSN: 2449-7959 (in Polish)

[22] SZYMANIK, B., PSUJ, G., LOPATO, P., et al. Multimodal fatigue progress monitoring of construction steel elements. Archives QIRT 2016. ISSN: 2371-4085. DOI: 10.21611/qirt.2016.039

[23] DALIRI, A. JOHN, S., WANG, C. H., et al. Wireless strain sensors using electromagnetic resonators. In Proceedings of ASME 2012 Conference on Smart Materials, Adaptive Structures and Intelligent Systems. Stone Mountain (USA), Sep 2012, p. 665-669. DOI: 10.1115/SMASIS2012-7954

[24] DALIRI, A., GALEHDAR, A., JOHN, S., et al. Wireless strain measurement using circular microstrip patch antennas. Sensors and Actuators A: Physical, 2012, vol. 184, no. 9, p. 86-92. DOI: 10.1016/j.sna.2012.07.003

[25] LANTZ, G. Crack Detection using a Passive Wireless Strain Sensor. Georgia Institute of Technology, 2011.
[26] YI, X., WU, T., WANG, Y., LEON, R. T., et al. Passive wireless smart-skin sensor using RFID-based folded patch antenna. International Journal of Smart and Nano Materials, 2011, vol. 2, no. 1, p. 22-38. DOI: 10.1080/19475411.2010.545450

[27] TATA, U., HUANG, H., CARTER, R. L., et al. Exploiting a patch antenna for strain measurements. Measurement Science and Technology, 2008, vol. 20, no. 1, p. 1-7. DOI: 10.1088/09570233/20/1/015201

[28] WONG, K. Design of Nonplanar Microstrip Antennas and Transmission Lines. Wiley, 1999. ISBN: 978-0-471-18244-3

[29] BALANIS, C. A. Antenna Theory: Analysis and Design. $3^{\text {rd }}$ ed. Hoboken: John Wiley \& Sons, 2005. ISBN: 978-1-119-09493-7

[30] PITRA, K., RAIDA, Z., LACIK, J. Low-profile circularly polarized antenna exploiting Fabry-Perot resonator principle. Radioengineering, 2015, vol. 24 no. 4, p. 898-905. DOI: $10.13164 /$ re.2015.0898

[31] BARTYZAL, J., BOSTIK, T., KOVACS, P., et al. Antenna arrays for tactical communication systems: A comparative study. Radioengineering, 2011, vol. 20, no. 4, p. 817-827.

[32] KOUMASIS, A. CHRONOPOULOS, S. K., ANGELIS, C. T., et al. Smart antennas with E-shaped patch for $3 \mathrm{G}$ applications. WSEAS Transactions on Communications, 2006, vol. 5, no. 9, p. 1636-1641.

[33] Structural Mechanics Module User's Guide, COMSOL Multiphysics 5.2

[34] RF Module User's Guide, COMSOL Multiphysics 5.2

[35] RAPTIS, V., TATSIS, G., CHRONOPOULOS, S. K., et al. Development and experimental measurements of a tunable antenna. Communications and Network, 2013, vol. 5, no. 3, p. 220-224. DOI: $10.4236 / \mathrm{cn} .2013 .53026$

[36] RAPTIS, V., TATSIS, G., VOTIS, C., et al. Active tuning antennas for wireless communication. In AIP Conference Proceedings, 2010, vol. 1203 , no. 1, p. 1058-1062. DOI: $10.1063 / 1.3322310$

[37] ELFERGANI, I., HUSSAINI, A. S., RODRIGUEZ, J., et al. Wideband tunable PIFA antenna with loaded slot structure for mobile handset and LTE applications. Radioengineering, 2014, vol. 23 , no. 1 , p. 345-355. ISSN: 1210-2512

\section{About the Authors ...}

Przemyslaw LOPATO was born in 1979 in Szczecin, Poland. He received his M.Sc. and Ph.D. from the West Pomeranian University of Technology in 2004 and 2008, respectively. Currently he is an Assistant Professor in the Dept. of Electrical and Computer Engineering (WPUT) responsible for Laboratory of Antennas and High Frequency Techniques. His research interests include nondestructive testing using microwave and terahertz methods, antennas and SHM sensors design.

Michal HERBKO (corresponding author) was born in 1992 in Szczecin, Poland. He received his M.Sc. in Electrical Engineering from the West Pomeranian University of Technology in 2016. His research interests include nondestructive testing, SHM sensors and microwave technique. 